\title{
Liver immunology and its role in inflammation and homeostasis
}

\author{
Mark W Robinson ${ }^{1}$, Cathal Harmon ${ }^{1}$ and Cliona O'Farrelly ${ }^{1,2}$
}

The human liver is usually perceived as a non-immunological organ engaged primarily in metabolic, nutrient storage and detoxification activities. However, we now know that the healthy liver is also a site of complex immunological activity mediated by a diverse immune cell repertoire as well as non-hematopoietic cell populations. In the nondiseased liver, metabolic and tissue remodeling functions require elements of inflammation. This inflammation, in combination with regular exposure to dietary and microbial products, creates the potential for excessive immune activation. In this complex microenvironment, the hepatic immune system tolerates harmless molecules while at the same time remaining alert to possible infectious agents, malignant cells or tissue damage. Upon appropriate immune activation to challenge by pathogens or tissue damage, mechanisms to resolve inflammation are essential to maintain liver homeostasis. Failure to clear 'dangerous' stimuli or regulate appropriately activated immune mechanisms leads to pathological inflammation and disrupted tissue homeostasis characterized by the progressive development of fibrosis, cirrhosis and eventual liver failure. Hepatic inflammatory mechanisms therefore have a spectrum of roles in the healthy adult liver; they are essential to maintain tissue and organ homeostasis and, when dysregulated, are key drivers of the liver pathology associated with chronic infection, autoimmunity and malignancy. In this review, we explore the changing perception of inflammation and inflammatory mediators in normal liver homeostasis and propose targeting of liver-specific immune regulation pathways as a therapeutic approach to treat liver disease.

Cellular \& Molecular Immunology (2016) 13, 267-276; doi:10.1038/cmi.2016.3; published online 11 April 2016

Keywords: homeostasis; immunology; inflammation; liver; tolerance

\section{INFLAMMATORY PROCESSES AND LIVER HOMEOSTASIS}

The human liver is classically perceived as a non-immunological organ, required for metabolic activities, nutrient storage and detoxification. We now know that the liver is also an immunologically complex organ, responsible for the production of acute phase proteins, complement components, cytokines and chemokines, and contains large, diverse populations of resident immune cells. ${ }^{1-3}$ In healthy individuals, the liver is constantly bombarded by a stream of dietary and commensal bacterial products with inflammatory potential. These gutderived molecules must be tolerated by the hepatic immune system, which, at the same time, is poised to respond to danger. In the healthy liver, constantly changing metabolic and tissue remodeling activity, combined with regular exposure to microbial products, results in persistent, regulated inflammation.
These inflammatory processes act in a tightly controlled fashion and are stimulated to additional activity only when the liver is required to rid itself of hepatotropic pathogens, malignant cells or toxic products of metabolic activity. Failure to clear such dangerous stimuli and resolve inflammation, leads to chronic infection, autoimmunity or tumor growth. This is inevitably associated with chronic pathological inflammation and disrupted tissue homeostasis, which can progress to fibrosis, cirrhosis and liver failure.

Inflammation is essential to combat infection; however, inflammatory mechanisms also underpin normal physiological events in the healthy body, including embryonic implantation, ${ }^{4}$ fetal development, ${ }^{5}$ involution post-partum and tissue repair. ${ }^{6}$ In the liver, homeostatic inflammatory processes control hemodynamic changes, capillary permeability, leukocyte migration into tissues and secretion of inflammatory mediators. This

\footnotetext{
${ }^{1}$ School of Biochemistry and Immunology, Trinity Biomedical Sciences Institute, Trinity College Dublin, Dublin D2, Ireland and ${ }^{2}$ School of Medicine, Trinity Biomedical Sciences Institute, Trinity College Dublin, Dublin D2, Ireland

Correspondence: Dr C O'Farrelly, School of Biochemistry and Immunology, Trinity Biomedical Sciences Institute, Trinity College Dublin, Dublin D2, Ireland. E-mail: cliona.ofarrelly@tcd.ie

Received: 19 November 2015; Revised: 8 January 2016; Accepted: 9 January 2016
} 


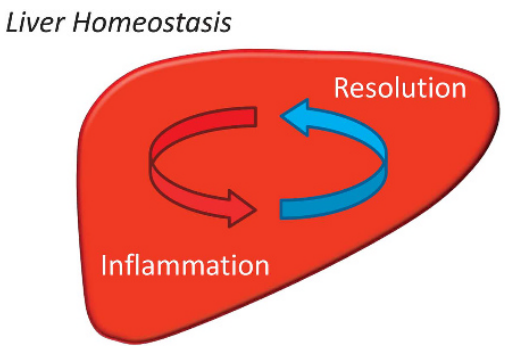

Liver Pathology

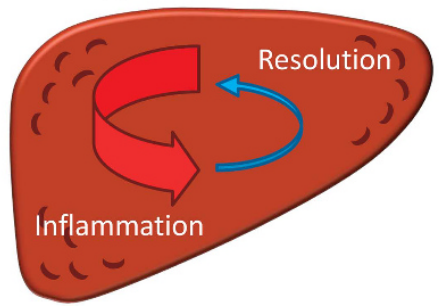

Acute liver failure

Sepsis

Chronic infection

Liver cirrhosis

HCC

Figure 1 The role of inflammatory processes in liver homeostasis and pathology. Inflammatory processes in the liver are involved in both homeostasis (organ and systemic) and pathology. Homeostatic inflammation is tightly regulated by mechanisms that act to resolve inflammation in order to avoid the pathological consequences of excessive inflammation.

homeostatic inflammation is tightly regulated and the activation of inflammatory processes is intimately linked to mechanisms that resolve inflammation and promote tissue regeneration (Figure 1). This controlled inflammation is essential to maintain tissue and organ homeostasis and yet, when dysregulated, drives pathology and organ damage (Figure 1). In this review, we demonstrate an emerging role for inflammation and inflammatory mediators in normal liver homeostasis, in regulating the liver immune system and in liver regeneration following various forms of liver damage. We propose that homeostatic inflammation should be viewed as a normal part of the healthy liver and that therapeutic strategies targeting liver disease be designed to restore these homeostatic inflammatory processes.

\section{THE IMMUNOLOGICAL STRUCTURE OF THE LIVER}

The liver functions as an important buffer between gut contents and systemic circulation $-80 \%$ of the hepatic blood supply is delivered from the gut via the portal vein. This low pressure blood supply is rich with harmless dietary and environmental antigens as well as molecules from the microflora of the gut. The liver must tolerate this immunogenic load while still providing immunosurveillance for pathogenic infections and malignant cells. Upon entering the liver venous blood from the gut mixes with oxygen-rich blood from the hepatic artery and drains through the hepatic sinusoids to the central veins through plates of hepatocytes. The sinusoids are lined by specialized liver sinusoidal endothelial cells (LSEC) that contain numerous fenestrations, allowing blood to pass through the LSEC layer to the underlying hepatocytes.

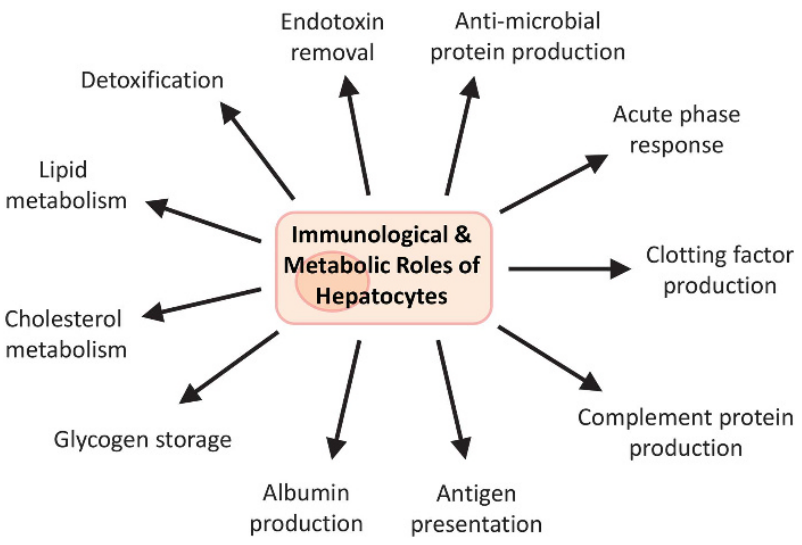

Figure 2 Immunological and metabolic roles of hepatocytes. Hepatocytes perform a number of important immunological roles, in addition to their essential metabolic roles. These include: the production of plasma proteins such as clotting factors, complement and antimicrobial proteins; the production of acute phase proteins upon local or systemic infection; and antigen presentation to T cells within the liver.

This organization allows for the rapid exchange of molecules from blood into hepatocytes and facilitates the removal and degradation of immunogenic molecules (for example, bacterial endotoxin) in the liver (Figure 2). Pattern recognition receptors (PRR) expressed by hepatocytes and liver-resident macrophages (known as Kupffer cells (KC)), bind to microbial associated molecular patterns (MAMP) $)^{7,8}$ and damage-associated molecular patterns (DAMP), ${ }^{9}$ which are present in high quantities in the blood arriving from the portal vein. Upon binding, these MAMPs and DAMPs are phagocytosed and subsequently degraded by hepatocytes and KCs, without the production of inflammatory mediators that usually accompany PRR signaling. This detoxification of blood from the gut protects the rest of the body from excessive immune activation and influences the unique immunological environment within the liver.

The low pressure blood flow, fenestrated endothelium and lack of a basement membrane ${ }^{10}$ also facilitates intimate interactions between resident immune cells and nonhematopoietic hepatic cells. These resident immune cell populate the liver sinusoids and the sub-endothelial compartment, the space of Disse, where lymph collects and flows into lymphatic vessels running along the portal tract. These resident immune cells include professional antigen presenting cell (APC) populations, myeloid cells, as well as innate and adaptive lymphoid cell populations. ${ }^{11-13}$ While several liver-resident immune cell populations are well recognized (for example, $\mathrm{KCs})$, the full spectrum of immune cells resident within the liver is still unclear. This is particularly true in humans, and further studies are required to define phenotypically distinct liver-resident immune cell populations. In the context of the healthy adult liver, these liver-resident populations play vital roles in regulating inflammation and maintaining organ homeostasis and the immunological roles of individual liver-resident immune cell populations are described in further detail in this issue of Cellular and Molecular Immunology. 


\section{Liver Myeloid Immune Cell Populations}

Macrophages are key detectors of microbial molecules and producers of inflammatory mediators in the body. KCs account for up to $90 \%$ of the total population of fixed macrophages in the body and constitute almost a third of the non-parenchymal cells in the liver. ${ }^{14} \mathrm{KCs}$ are equipped with a massive array of PPRs, ${ }^{15}$ complement receptors ${ }^{16}$ and $\mathrm{Fc}$ receptors ${ }^{17}$ through which they respond with increased phagocytic activity and production of inflammatory cytokines. They have essential roles in immune regulation, tissue repair and liver regeneration ${ }^{18}$ and are capable of responding to cytokine, Toll-like receptor (TLR), ${ }^{19}$ RIG-like receptor and NOD-like receptor signaling. ${ }^{20}$

Dendritic cell (DC) populations, including both myeloid DCs and plasmacytoid DCs, are found in the healthy liver. Hepatic DC populations are described as phenotypically immature although they can stimulate strong T-cell responses in certain situations. ${ }^{21}$ Recently a sub-population of human hepatic CD141+ DCs have been shown to be potent cytokine producers and activators of $\mathrm{T}$ cells. ${ }^{11}$

Myeloid-derived suppressor cells (MDSC) are also present in the healthy liver $^{22}$ and are expanded during chronic liver disease. ${ }^{23}$ MDSCs are defined by their ability to suppress T-cell activation through the production of the immunosuppressive molecules IL-10, transforming growth factor (TGF) $\beta$ and arginase. ${ }^{24}$ Granulocytic cells, such as neutrophils, are thought to be largely absent in the healthy liver, only accumulating in response to infection and inflammation. ${ }^{25}$ However, neutrophils and their progenitors share several phenotypic markers with MDSCs and comprehensive data characterizing these populations in the human liver are lacking.

\section{Liver Lymphoid Immune Cell Populations}

The diverse range of innate lymphocytes in the adult liver includes natural killer (NK) cells, NK T cells (NKT) (including populations of CD1d-restricted invariant NKT cells), mucosal associated invariant $\mathrm{T}$ cells and $\gamma \delta \mathrm{T}$ cells. ${ }^{12,26-28}$ Hepatic innate lymphocyte populations are potent cytokine producers and influence both innate and adaptive immune responses in the liver. The repertoire of liver innate lymphocytes is strikingly different between mice and humans. In mice, NKT cells and NK cells make up to $40 \%$ and $10 \%$ of total liver lymphocytes respectively, while in humans, these percentages are reversed, with NK cells predominating. ${ }^{29}$ In humans, CD56 $6^{\text {bright }} \mathrm{NK}$ cells are particularly enriched in the liver where they constitute over $50 \%$ of the total hepatic NK population, compared with $10-15 \%$ in peripheral blood. ${ }^{30,31}$ In mice, invariant NKT cells preferentially home to the liver where they adhere via LFA/ICAM binding, and form a highly tissueresident immune cell population. ${ }^{32}$

Populations of adaptive lymphocytes, including classic major histocompatibility complex (MHC)-restricted $\mathrm{CD}^{+}$and $\mathrm{CD} 8^{+}$ $\mathrm{T}$ cells as well as B cells, are found in healthy liver. The liver is particularly enriched in $\mathrm{CD}^{+}{ }^{+} \mathrm{T}$ cells, activated $\mathrm{T}$ cells and memory $\mathrm{T}$ cells. ${ }^{13,33}$ Accumulation of these $\mathrm{T}$-cell subsets in the liver is associated with T-cell apoptosis and deletion leading to the liver having been described as a 'graveyard' for $\mathrm{T}$ cells. $^{34,35}$ Populations of B cells are also present in the human liver, where they account for up to $8 \%$ of the total lymphocyte population..$^{13}$ Specific hepatic B cell subpopulations, such as the innate-like $\mathrm{CD} 5+\mathrm{B}$ cell population, are further expanded in the liver during hepatotropic viral infection. ${ }^{36,37}$

\section{Hematopoietic Progenitor Cell Populations in the Liver}

While hematopoietic cell development is classically assumed to be limited to the bone marrow in healthy adults, it has been hypothesized that some hepatic immune populations differentiate locally. ${ }^{38,39}$ The ability of the liver to act as a site of hematopoiesis when under stress is well described and hematopoietic stem cells are thought to contribute to mixed chimerism following liver transplant in murine models. ${ }^{40}$ Moreover, purified liver hematopoietic progenitor cells have been shown to reconstitute immune cell populations following lethal irradiation in mice. ${ }^{41}$ The adult human liver also contains populations of progenitor cells, which express surface markers characteristic of immature hematopoietic cells and form multi-lineage hematopoietic colonies upon in vitro culture. ${ }^{38,39}$ These hepatic myeloid and lymphoid progenitor populations may contribute to the development of phenotypically distinct liver-resident immune cell populations through local hepatic immune cell differentiation.

\section{Immune-Regulating Liver Non-Hematopoietic Cell Populations}

In addition to hepatic immune cell populations, nonhematopoietic cells in the liver play key roles in local and systemic innate immunity and inflammation. LSECs, hepatocytes and hepatic stellate cells (HSC) all express a range of PRRs. ${ }^{19,42,43}$ Expression of TLRs, carbohydrate receptors and scavenger receptors by non-immune cells in the liver complements KC detection and clearance of MAMPs from the portal blood supply and regulates the production of inflammatory mediators from non-immune cells within the liver.

LSECs, and hepatocytes express variable levels of Class II MHC molecules and are capable of presenting antigens to classical $\mathrm{T}$ cells. ${ }^{1,21}$ Under inflammatory conditions LSEC-primed $\mathrm{T}$ cells can develop into functional $\mathrm{T}$ effector cell populations, in the absence of CD4+ T-cell activation, and contribute to pathogen immunity. ${ }^{44}$ Murine hepatocytes also express the MHC-like molecule CD1d, enabling lipid presentation to invariant NKT. ${ }^{45}$ In contrast, it has been difficult to demonstrate CD1d expression by healthy human hepatocytes, although it is increased in the context of hepatitis $\mathrm{C}$ virus infection. ${ }^{46}$

\section{THE LIVER MICROENVIRONMENT AND IMMUNE REGULATION}

The anatomical structure, resident immune cell repertoire and state of constant stimulation in the liver combine to create a unique cytokine/growth factor milieu. This microenvironment determines the balance between tolerance and inflammation in the healthy liver. The hepatic blood supply is a significant contributor to the unique liver microenvironment. Cells within the liver are subject to persistent signaling from dietary and commensal molecules, which induces a state of tolerance as 
discussed in more detail below. The healthy adult liver has an active and complex cytokine milieu, which includes basal expression of pro-inflammatory (IL-2, IL-7, IL-12, IL-15 and interferon (IFN) $\gamma$ ) and anti-inflammatory (IL-10, IL-13 and TGF $\beta$ ) cytokines. ${ }^{47,48}$ This cytokine milieu exists in the absence of infection or pathological inflammation, and presumably arises through normal physiological processes within the healthy liver. These processes likely include PRR signaling induced by gut-derived molecules in both non-hematopoietic and myeloid cell populations, as well as cytokine production by activated hepatic lymphoid immune cell populations. ${ }^{49}$

The hepatic microenvironment is further influenced by the high levels of dietary fats and carbohydrates in the hepatic blood supply. Carbohydrates are taken up by hepatocytes and stored as glycogen, while dietary fats, transported from the gut as chylomicrons, are processed into a range of lipoproteins that in turn distribute cholesterol and triglycerides throughout the body (Figure 2). Importantly these metabolic processes are intimately linked to liver inflammation through the inflammatory effects of metabolites such as succinate $e^{50}$ as well as triglyceride and cholesterol levels, which promote TLR signaling and inflammasome activation. ${ }^{51}$ The metabolic regulation of inflammation is important in non-alcoholic fatty liver disease where elevated pro-inflammatory cytokines, which contribute to liver fibrosis, are observed. ${ }^{52}$ In mouse models, this pro-inflammatory profile can be replicated by a high-fat diet, driven in part by the sensitization of hepatocytes to TLR agonists by saturated fatty acids. ${ }^{53}$ Metabolic regulation of liver hepatocytes is also evident in hepatitis $B$ virus and hepatitis $C$ virus infections, where metabolic changes in infected hepatocytes promote viral replication. ${ }^{54,55}$ It is likely that these metabolic changes also influence the inflammatory immune response to viral infection.

Indeed, these metabolic links with inflammation extend beyond hepatocytes and also influence macrophage and DC functions. Both macrophages and DCs undergo metabolic reprogramming upon activation, switching from oxidative phosphorylation to aerobic glycolysis, termed the Warburg effect. ${ }^{56}$ This switch is essential for the production of proinflammatory mediators in macrophages however the influence of metabolism on liver KC function is presently unknown. At normoxia, the switch to aerobic glycolysis in macrophages results in increased succinate levels that in turn activate HIF1 $\alpha$ and IL1 $\beta$ production. ${ }^{50}$ HIF1 $\alpha$ is also activated by hypoxia yet despite the liver being in a constant state of low oxygen tension (due to blood from the portal vein), a hypoxia response is not induced in healthy hepatic cells. ${ }^{57}$ This suggests that cells within the liver may have a unique response to metabolic signals that are known to drive inflammation and these unique metabolic signals likely contribute to the regulation of liver-immigrating immune cell populations. A deeper understanding of the role of the dynamic liver microenvironment in organ homeostasis is required to provide a context to the changes that occur during human liver pathology.
INFLAMMATORY PROCESSES IN THE HEALTHY LIVER

Inflammation and inflammatory mediators, generated by liverresident immune cell populations and non-hematopoietic cells, play essential roles in maintaining local liver and systemic homeostasis. These homeostatic roles must be recognized when considering the role of inflammation and liver-resident immune cell populations in liver disease and pathology. Liver inflammation should be considered as a highly dynamic and complex network of responses, which collectively aim to maintain organ and also systemic homeostasis in healthy individuals.

\section{The Tolerogenic Liver}

The healthy liver is often described as being immunologically tolerogenic ${ }^{58,59}$ nevertheless it is evident that rapid and robust liver immune responses are successfully generated in many circumstances. The concept that the liver is an immunologically tolerant organ arose in the transplantation field when it was first observed in pigs that allogeneic liver transplantation was significantly better tolerated than other allogeneic organ transplantation, which induced rapid rejection. ${ }^{60}$ This concept is supported by the low levels of immunosuppression generally required by liver transplant recipients. Indeed, in certain individuals, immunosuppression can be completely stopped following liver transplantation without subsequent graft rejection. ${ }^{61}$ Furthermore, the ability of hepatic tolerance to induce systemic tolerance to co-transplanted organs highlights the powerful tolerogenic properties of the liver. ${ }^{62}$

Resident myeloid cells contribute to the maintenance of hepatic tolerance. KCs respond to bacterial endotoxin by producing anti-inflammatory cytokines such as IL-10 and prostaglandins. ${ }^{63,64}$ These downregulate expression of co-stimulatory molecules on APCs, preventing activation of CD4+ $\mathrm{T}$ cells and limiting the adaptive immune response. ${ }^{65,66}$ Presentation of particulate antigens by KCs preferentially expands IL-10 producing $\mathrm{T}$ regulatory cell populations inducing antigen-specific tolerance. ${ }^{67}$ Similarly, hepatic myeloid DCs are less potent activators of $\mathrm{T}$ cells and produce significantly more IL-10 compared with spleen derived myeloid DCs. ${ }^{68-70}$ Hepatic plasmacytoid DCs also appear phenotypically immature and are not effective $\mathrm{T}$-cell activators ex vivo; however, activation via growth factors or TLR agonists induces maturation and effective antigen presentation. ${ }^{71}$ Hepatic plasmacytoid DCs have also been shown to be capable of IL-10 production and activation of regulatory $\mathrm{T}$ cells. ${ }^{72}$ In addition to these professional APC populations in the liver, LSECs and hepatocytes possess the ability to directly present antigen to $\mathrm{T}$ cells. ${ }^{1,21}$ Under certain conditions HSCs may also directly present antigen to $\mathrm{T}$ cells as well as influence antigen presentation as a bystander cell. ${ }^{73}$ The presentation of antigens in the liver biases $\mathrm{T}$ cells towards tolerance due to a lack of co-stimulatory molecules and $\mathrm{CD}^{+} \mathrm{T}$-cell help, required for efficient T-cell differentiation. ${ }^{74,75}$

The tolerogenic liver environment is further maintained by regulatory myeloid populations such as MDSCs. MDSCs mediate their suppressive activity through the production of the immunosuppressive cytokines IL-10 and TGF $\beta$, and the 


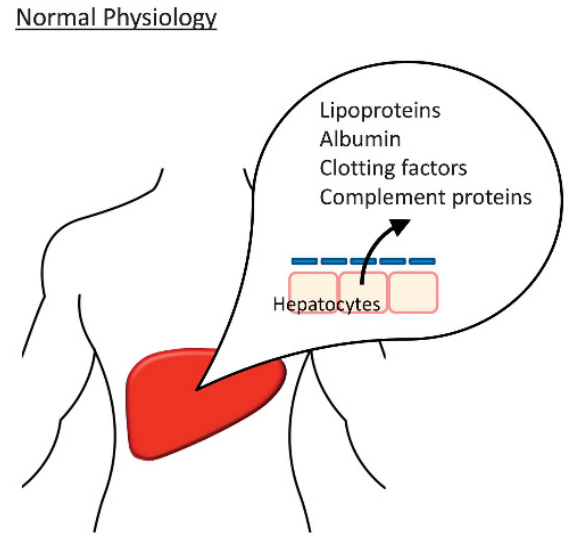

Acute Phase Response

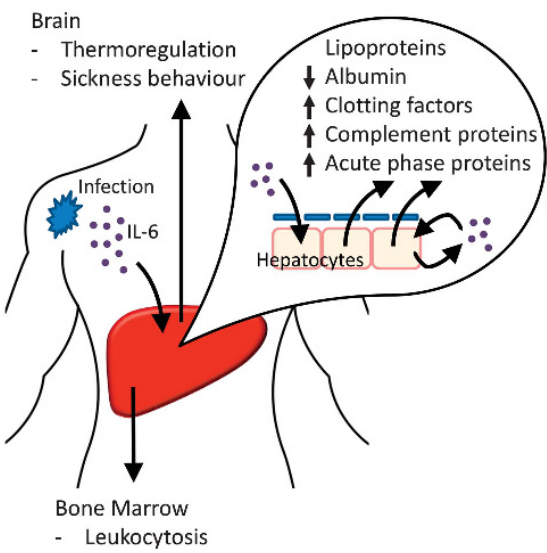

Figure 3 Regulation of systemic homeostasis by the liver. In a healthy individual, the liver produces a range of serum proteins including albumin, clotting factors and complement. During acute infection hepatocytes are induced to produce a range of antimicrobial proteins, inflammatory mediators, coagulation factors and opsonins, collectively known as the acute phase response. Inflammatory cytokines produced in the liver (for example, IL-6) enhance the acute phase response, alter thermoregulation and induce leukocytosis.

production of arginase and IDO, which limit essential amino acids required for immune cell activation and proliferation. ${ }^{24}$ Transmigration of monocytes through LSECs leads to MDSC differentiation $^{76}$ and MDSCs are activated during the liver acute phase response $\mathrm{e}^{77}$ contributing to the immunoregulatory potential of the liver.

\section{Systemic Homeostasis and the Acute Phase Response}

A key systemic function of the liver is serum protein production. The liver normally synthesizes the majority of serum proteins, including complement proteins, albumin, fibrinogen, clotting factors, transport proteins, protease inhibitors and lipoproteins (Figure 3). These proteins are involved in the systemic transport of nutrients, in the regulation of blood osmotic pressure and act as inactive precursors of several innate immune mediators. The liver also has a central role in detecting and responding to inflammatory signals from other sites in the body (Figure 3). During the early stages of extra-hepatic inflammation, cytokines produced by immune cells enter the blood stream and are detected by liver hepatocytes, which initiate the systemic acute phase response (APR). ${ }^{78}$ Hepatocytes increase acute phase protein production by orders of magnitude and also synthesize IL-6, which acts to amplify the APR.

The acute phase proteins produced by hepatocytes have direct effector function (Table 1) and are responsible for the systemic effects of inflammation, which promote pathogen clearance. ${ }^{78-80}$ The acute phase proteins drive a range of mechanisms throughout the body including leukocytosis in the bone marrow, changes in the brain that mediate pyrexia and alter behavior, and massive immune cell infiltration to the site of initial inflammation. At the same time the APR includes a range of processes to limit excessive inflammation. These processes include the inhibition of neutrophil function by protease inhibitors, such as $\alpha_{2}$-macroglobulin, the inhibition of TNF production from KC by C-reactive protein, ${ }^{81}$ and the recruitment of suppressive MDSC populations by serum amyloid A. ${ }^{77}$
These processes act to limit bystander tissue damage caused by the inflammatory process and enhance the repair process.

\section{Liver Immunity and Resolving Fibrosis}

While maintaining an overall tolerogenic environment, the hepatic immune system must be capable of rapid, controlled responses to tumor cells and pathogenic microorganisms. Many pathogens, including several species of viruses, bacteria and parasites, specifically target the liver. ${ }^{58}$ Effective local immunity is essential for detecting and clearing these hepatotropic pathogens. During acute liver insult activated KCs can become potent producers of pro-inflammatory cytokines such as IL-1, IL- 6 and TNF- $\alpha$ as well chemokines such as MIP- $1 \alpha$ and RANTES. ${ }^{82,83}$ This KC pro-inflammatory response is induced following signaling via MyD88-independent TLRs (for example, TLR3), but not MyD88-dependent pathways, which instead induce IL-10 production. $^{84}$ Potent proinflammatory CD141+ myeloid DCs have also been demonstrated in healthy adult liver, capable of inducing IFN- $\gamma$ and IL-17 production from $\mathrm{T}$ cells. ${ }^{11}$ In this inflammatory microenvironment, liver-primed $\mathrm{T}$ cells can develop into functional $\mathrm{T}$ effector cell populations and mediate pathogen clearance, even in the absence of classical CD4+ T cell help. ${ }^{44}$

Acute liver inflammation leads to the recruitment and activation of leukocyte populations, and the induction of fibrotic responses at the site of inflammation, ${ }^{85}$ as summarized in Figure 4. The resolving fibrosis observed during acute injury acts to protect surviving hepatocytes by reducing pro-apoptotic signaling and increasing resistance to a range of toxins. ${ }^{86}$ This fibrotic process is regulated by inflammatory cytokines and growth factors, released by leukocytes that traffic to the damaged tissue. These cytokines include TNF $\alpha$, IL-6, plateletderived growth factor and TGF $\beta$. These cytokines lead to activation and proliferation of HSCs, which are potent producers of extra-cellular matrix components, including $\alpha$-smooth muscle actin and type I collagen. ${ }^{87}$ Liver fibrosis is 
Table 1 Serum protein synthesis by the liver during the acute phase response

\begin{tabular}{|c|c|c|}
\hline Proteins induced in APR & Examples & Immune function \\
\hline Complement proteins & C3, C4 and C9 & $\begin{array}{l}\text { Enhance phagocytosis, act as chemoattractants, induce } \\
\text { cell degranulation, enhance vascular permeability and } \\
\text { induce bacterial cell lysis }\end{array}$ \\
\hline Iron-binding proteins & Haptoglobin, hemopexin, ferritin and hepcidin & $\begin{array}{l}\text { Act to reduce free iron in the serum and antimicrobial } \\
\text { functions }\end{array}$ \\
\hline Antimicrobial proteins & Liver expressed antimicrobial peptide 2 , hepcidin & Antimicrobial activity \\
\hline Clotting factors & $\begin{array}{l}\text { Fibrinogen, prothrombin, factor VIII, factor IX and Von } \\
\text { Willebrand factor }\end{array}$ & Enhance coagulation \\
\hline Inflammatory proteins & $\begin{array}{l}\text { IL-6, lipopolysaccahride-binding protein and secreted } \\
\text { phospholipase } A_{2}\end{array}$ & $\begin{array}{l}\text { Enhance pro-inflammatory signals and potentiate the } \\
\text { APR }\end{array}$ \\
\hline $\begin{array}{l}\text { Lectins, pentraxins, ficolins } \\
\text { and collectins }\end{array}$ & $\begin{array}{l}\text { C-reactive protein, mannose-binding lectin, collectin liver } 1 \text {, } \\
\text { ficolin-2 and serum amyloid } P\end{array}$ & Active complement and enhance phagocytosis \\
\hline Protease inhibitors & $\alpha_{2}$-Macroglobulin, $\alpha_{1}$-antichymotrypsin and $\alpha_{1}$-antitrypsin & $\begin{array}{l}\text { Anti-inflammatory functions via the inhibition of coagu- } \\
\text { lation, neutrophils and mast cells }\end{array}$ \\
\hline
\end{tabular}

Abbreviation: ARP, acute phase response.

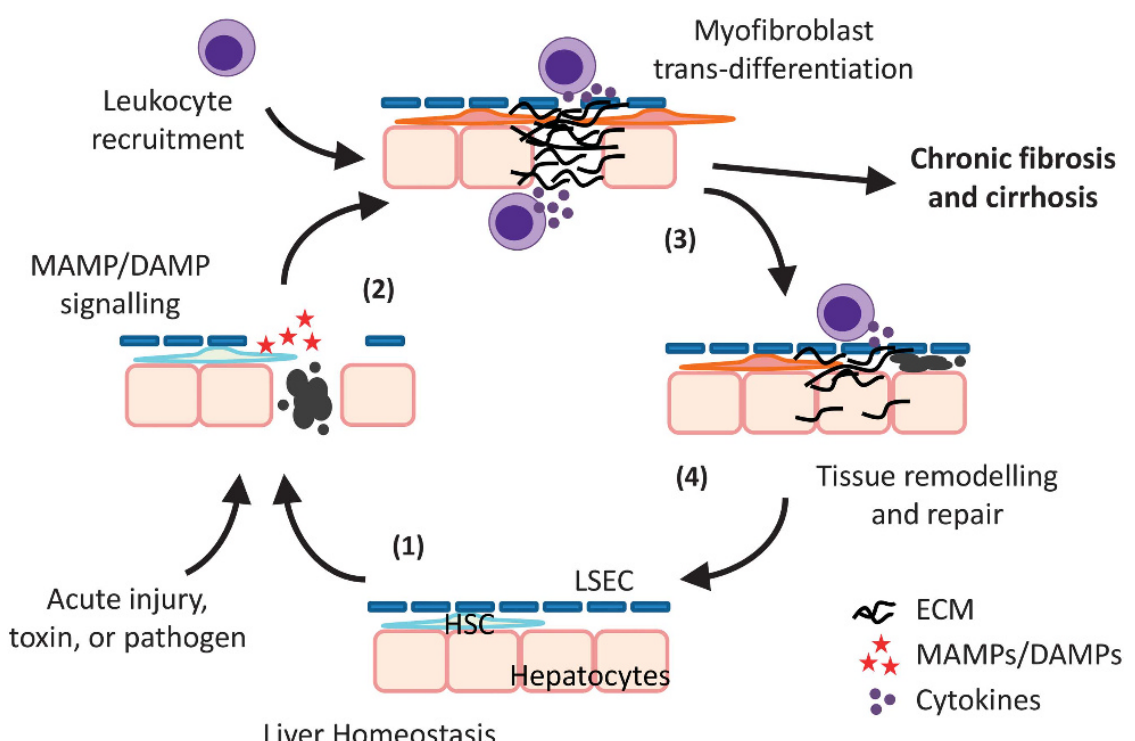

Figure 4 Maintenance of local homeostasis in the liver in response to liver damage. Inflammatory processes are vital to maintain liver homeostasis following cell death or infection. Upon acute injury, cell death or infection, apoptotic hepatocytes release a variety of DAMPs and/or MAMPs (1) that are recognized by and activate neighboring hepatocytes, HSCs, and liver-resident immune cell populations. Activated cells secrete inflammatory mediators leading to leukocyte recruitment and HSC trans-differentiation into myofibroblasts, which initiate fibrosis through the synthesis of extra-cellular matrix components (2). The initiation of inflammation leads to the expression of proresolving factors from recruited leukocytes and myofibroblast apoptosis (3), enabling tissue regeneration and a return to homeostasis (4). If this resolution phase does not occur persistent inflammation results in the progressive development of liver fibrosis and eventual cirrhosis. Abbreviations: DAMPs, damage-associated molecular patterns; ECM, extra-cellular matrix components; HSCs, hepatic stellate cells; MAMPs, microbial associated molecular patterns.

often considered a feature of pathology but resolving fibrosis is also essential for liver wound repair and restoration of tissue homeostasis (Figure 4). Fibrosis only becomes clinically relevant when it alters tissue structure and function due to dysregulated or excessive inflammation.

In the resolution phase of acute liver fibrosis, macrophages produce a range of pro-resolution mediators, which increase expression of matrix metalloproteinases and suppress matrix metalloproteinase inhibitors. ${ }^{88}$ At the same time, NK cell-mediated cytotoxicity against HSCs contributes to the regulation of intrahepatic fibrosis. Trans-differentiation of activated HSCs into myofibroblasts alters the balance of activating and inhibitory cell receptor ligands such that they are targeted for deletion by NK cells via TRAIL-, FasLand NKG2D-dependent mechanisms. ${ }^{89,90}$ These multifaceted interactions between immune cell subsets that regulate the repair process lead many to consider wound healing as a critical component of the innate immune response to tissue damage. 


\section{Inflammation and Liver Regeneration}

The capacity of the liver to fully regenerate after injury is essential for the maintenance of the liver's important functions in the control of metabolism and xenobiotic detoxification. This regenerative capacity is driven by the proliferation of existing mature hepatocytes in response to environmental cues. ${ }^{91}$ The regeneration potential of the liver is driven by inflammatory mediators (for example, IL- $1 \alpha$, TNF $\alpha$ and IL-6), growth factors (for example, hepatocyte growth factor and epidermal growth factor) and liver-resident immune cell populations. ${ }^{92}$ The importance of IL- 6 is emphasized by the impaired liver regeneration observed in mice with targeted disruption of IL-6, which have reduced hepatocyte proliferation that can be restored with a single pre-operative dose of IL-6. ${ }^{93}$ Impaired liver regeneration is also observed in mice treated with antibodies targeting TNF $\alpha .^{94}$ The pro-regeneration effect of TNF $\alpha$ requires expression of inducible nitric oxide synthase, which blocks the potential pro-apoptotic effect of TNF $\alpha$ signaling, and highlights a small part of the complexity of inflammatory signals required to regulate liver regeneration. ${ }^{95}$

KCs play a central role in this liver regeneration via release of IL- 6 and TNF $\alpha$, which promotes hepatocyte proliferation, and KC depletion impedes subsequent liver regeneration. ${ }^{96}$ This KC activation is driven by neutrophil recruitment to the liver, in response to inflammatory signals, in an ICAM-1-dependent manner. ${ }^{96}$ The complement proteins $\mathrm{C} 3$ and $\mathrm{C} 5$ also play important roles in priming KCs and promoting hepatocyte proliferation following partial hepatectomy. ${ }^{97}$ In addition to these pro-regeneration properties, liver-resident immune cell populations can also inhibit liver regeneration. ${ }^{98}$ Depletion of NK cells enhances liver regeneration due to reduced IFN $\gamma$ production, which acts to induce hepatocyte cell cycle arrest and inhibits hepatocyte proliferation. ${ }^{99,100}$ Depletion of NKT cells in hepatitis B virus transgenic mice also enhances liver regeneration due to reduced production of IFN $\gamma$ and $\mathrm{TNF} \alpha{ }^{101}$ These liver-resident immune cell populations act as a negative feedback mechanism, regulating liver regeneration and returning the liver to homeostasis.

\section{TARGETING IMMUNE DYSREGULATION AS A THERAPEUTIC STRATEGY IN LIVER DISEASE}

Dysregulation of liver inflammation is a hallmark of chronic infection, autoimmunity and malignancy, which is mediated by multiple overlapping pathways in different liver diseases. While homeostatic inflammation and liver fibrosis are aspects of the healthy adult liver, a lack of resolution or chronic liver injury lead to progressive liver fibrosis and permanent liver damage. In these situations, pathological inflammation promotes the progression of liver fibrosis to cirrhosis and establishes a dysregulated balance between inflammation and immunosuppression within the liver. Approaching liver disease as a range of overlapping pathways leading to the dysregulation of homeostatic inflammatory processes provides novel avenues for the development of future therapies targeting inflammation and resolution within the liver.
Excessive or persistent inflammation characterizes a range of liver diseases. Persistent activation of innate immune detection pathways, due to chronic infection, tissue damage, excess consumption of alcohol or fat, or tumor growth, leads to the classic features of pathological liver inflammation. Persistent inflammatory signals, produced by a range of immune cell and non-hematopoietic cell populations, maintain HSC-derived hepatic myofibroblasts in an activated state. ${ }^{102}$ This limits myofibroblast senescence and reduces the ability of NK cells to induce myofibroblast apoptosis. ${ }^{98}$ Within the diseased liver, excessive inflammation results in the loss of liver tolerogenic mechanisms, promoting further inflammation. Inflammatory monocyte-derived macrophages are recruited to the liver where they promote fibrosis, ${ }^{103}$ and reduce the ability of KCs to promote $\mathrm{T}$ regulatory cell development. ${ }^{67}$ This disruption of hepatic tolerance has important clinical consequences as liver disease develops. As an example the spread of bacterial products in advanced cirrhosis/decompensation can lead to a pro-inflammatory cytokine storm and eventual systemic organ failure. ${ }^{104}$ Where treatment options are available clinically, such as in autoimmune disorders, these rely on the use of general immunosuppressive drugs. ${ }^{105}$ In this context, therapeutic strategies aimed at enhancing the normal tolerogenic liver mechanisms that lead to the resolution of inflammation, fibrosis regression and hepatocyte regeneration, may augment the existing immunosuppressive treatments. The potential of such strategies can be seen in results from a recent clinical trial, using a combination of granulocyte colony-stimulating factor and erythropoietin to enhance liver regeneration, which improved 12-month survival for patients with advanced cirrhosis and significantly reduced liver severity scores. ${ }^{106}$

Normal liver tolerogenic mechanisms can also act to promote the persistence of liver pathogens, such as hepatitis $\mathrm{C}$ virus, and the growth of primary and metastatic tumors, which in time establishes a state of dysregulated inflammation. A number of pathogens specifically target the liver ${ }^{58}$ and the liver is also a common site of primary malignancy and metastasis. The presentation of pathological antigens in the liver can actively suppress immune responses, thus inducing a state of immune tolerance to the pathogen or tumour. ${ }^{58,74,75,107}$ At the same time, innate immune activation, in response to MAMPs or DAMPs released during infection or tumor growth, results in persistent inflammation and the upregulation of a number of immune regulatory pathways aimed at minimizing excessive tissue damage. This includes expansion of tumorpromoting immunoregulatory cell populations such as MDSCs, ${ }^{24,108}$ epigenetic and metabolic changes resulting in immune cell tolerance, ${ }^{109}$ induction of negative regulators of pro-inflammatory signaling pathways, ${ }^{110}$ and development of T-cell exhaustion. ${ }^{107,111}$ Targeting these immune regulatory pathways in liver disease could reduce liver pathology (via promotion of regulatory mechanisms) or induce pathogen/ tumor clearance (via inhibition of regulatory mechanisms). One such strategy, using immune checkpoint inhibitors to reverse T-cell exhaustion, is showing promise in the field of cancer therapy as well as in the context of liver disease. A phase 
II clinical trial of Tremelimumab (which targets cytotoxic T-lymphocyte-associated protein 4), in patients with hepatitis $C$ virus infection and hepatocellular carcinoma, resulted in favorable antitumor activity and antiviral activity, including transient complete viral response in three patients. ${ }^{112}$ These results highlight the potential for therapeutically targeting immune tolerance in the liver.

\section{EPILOGUE: THE HEALTHY IMMUNOLOGICAL LIVER}

Inflammatory mechanisms are crucial to maintaining liver homeostasis as well as protecting the body from pathogens, tumors and tissue damage. Hepatic inflammatory mechanisms initiate, mediate and resolve systemic and local immune responses and at the same time contribute to liver pathology. The diverse repertoire of immune cell populations in the liver, together with the inflammatory potential of non-hematopoietic hepatic cells, plays a central role in both homeostatic and pathological inflammation within the liver. The complex inflammatory and immunoregulatory interplay within the liver is required to maintain organ and systemic homeostasis, as well as mobilize complementary inflammatory mechanisms to protect against infection, metastasis and tissue damage. We are at last beginning to dissect out the molecular mechanisms involved in these apparently contradictory inflammatory processes and to understand how inflammation is responsible for both normal liver homeostasis and function and also for liver pathology.

\section{KEY CONCEPTS}

1. The healthy adult liver contains large populations of resident myeloid and lymphoid immune cells.

2. Inflammatory mechanisms in the healthy liver maintain local organ and systemic homeostasis.

3. Despite a bias toward immune tolerance, hepatic immune cells can induce robust pro-inflammatory responses upon tissue damage or infection.

4. The liver plays a central role in the sensing of and the response to systemic inflammation.

5. Excessive or dysregulated inflammatory activity leads to the pathology associated with autoimmune, infectious or malignant hepatic disease.

\section{CONFLICT OF INTEREST}

The authors declare no conflict of interest.

\section{ACKNOWLEDGEMENTS}

We acknowledge funding from Science Foundation Ireland (grant \# 12/IA/1667) and the Health Research Board (grant \# HRA-POR-2013424). In addition, we gratefully acknowledge the on-going research contributions from the Liver Transplant Unit at St. Vincent's University Hospital.

1 Crispe IN. The liver as a lymphoid organ. Annu Rev Immunol 2009; 27: 147-163.
2 Nemeth E, Baird AW, O'Farrelly C. Microanatomy of the liver immune system. Semin Immunopathol 2009; 31: 333-343.

3 O'Farrelly C, Crispe IN. Prometheus through the looking glass: reflections on the hepatic immune system. Immunol Today 1999; 20: 394-398.

4 Thouas GA, Dominguez F, Green MP, Vilella F, Simon C, Gardner DK. Soluble ligands and their receptors in human embryo development and implantation. Endocr Rev 2015; 36: 92-130.

5 Wang J, Knaut $\mathrm{H}$. Chemokine signaling in development and disease. Development 2014; 141: 4199-4205.

6 Leoni G, Neumann P-A, Sumagin R, Denning TL, Nusrat A. Wound repair: role of immune-epithelial interactions. Mucosal Immunol 2015; 8: 959-968.

7 Janeway CA. The immune system evolved to discriminate infectious nonself from noninfectious self. Immunol Today 1992; 13: 11-16.

8 Takeuchi O, Akira S. Pattern recognition receptors and inflammation. Cell 2010; 140: 805-820.

9 Kubes P, Mehal WZ. Sterile inflammation in the liver. Gastroenterology 2012; 143: 1158-1172.

10 Wisse E, Braet F, Luo D, De Zanger R, Jans D, Crabbé E et al. Structure and function of sinusoidal lining cells in the liver. Toxicol Pathol 1996; 24: 100-111.

11 Kelly A, Fahey R, Fletcher JM, Keogh C, Carroll AG, Siddachari R et al. $\mathrm{CD} 141^{+}$myeloid dendritic cells are enriched in healthy human liver. J Hepatol 2014; 60: 135-142.

12 Doherty DG, Norris S, Madrigal-Estebas L, McEntee G, Traynor O, Hegarty JE et al. The human liver contains multiple populations of NK cells, T cells, and CD3+CD56+ natural T cells with distinct cytotoxic activities and Th1, Th2, and Th0 cytokine secretion patterns. J Immunol 1999; 163: 2314-2321.

13 Norris S, Collins C, Doherty DG, Smith F, McEntee G, Traynor O et al. Resident human hepatic lymphocytes are phenotypically different from circulating lymphocytes. J Hepatol 1998; 28: 84-90.

14 Bilzer M, Roggel F, Gerbes AL. Role of Kupffer cells in host defense and liver disease. Liver Int 2006; 26: 1175-1186.

15 Su GL, Klein RD, Aminlari A, Zhang HY, Steinstraesser L, Alarcon WH et al. Kupffer cell activation by lipopolysaccharide in rats: role for lipopolysaccharide binding protein and toll-like receptor 4. Hepatology 2000; 31: 932-936.

16 Schieferdecker HL, Schlaf G, Jungermann K, Götze O. Functions of anaphylatoxin $\mathrm{C} 5 \mathrm{a}$ in rat liver: direct and indirect actions on nonparenchymal and parenchymal cells. Int Immunopharmacol 2001; 1: 469-481.

17 van Egmond $M$, van Garderen $E$, van Spriel $A B$, Damen $C A$, van Amersfoort ES, van Zandbergen $\mathrm{G}$ et al. FcalphaRI-positive liver Kupffer cells: reappraisal of the function of immunoglobulin $A$ in immunity. Nat Med 2000; 6: 680-685.

18 Elsegood CL, Chan CW, Degli-Esposti MA, Wikstrom ME, Domenichini A, Lazarus $\mathrm{K}$ et al. Kupffer cell-monocyte communication is essential for initiating murine liver progenitor cell-mediated liver regeneration. Hepatology 2015; 62: 1272-1284.

19 Wu J, Meng Z, Jiang M, Zhang E, Trippler M, Broering R et al. Toll-like receptor-induced innate immune responses in non-parenchymal liver cells are cell type-specific. Immunology 2010; 129: 363-374.

20 Miura K, Yang L, van Rooijen N, Brenner DA, Ohnishi H, Seki E. Toll-like receptor 2 and palmitic acid cooperatively contribute to the development of nonalcoholic steatohepatitis through inflammasome activation in mice. Hepatology 2013; 57: 577-589.

21 Thomson AW, Knolle PA. Antigen-presenting cell function in the tolerogenic liver environment. Nat Rev Immunol 2010; 10: 753-766.

22 Chen S, Akbar SMF, Abe M, Hiasa Y, Onji M. Immunosuppressive functions of hepatic myeloid-derived suppressor cells of normal mice and in a murine model of chronic hepatitis B virus. Clin Exp Immunol 2011; 166: 134-142.

23 Pallett LJ, Gill US, Quaglia A, Sinclair L V, Jover-Cobos M, Schurich A et al. Metabolic regulation of hepatitis $B$ immunopathology by myeloid-derived suppressor cells. Nat Med 2015; 21: 591-600.

24 Gabrilovich DI, Nagaraj S. Myeloid-derived suppressor cells as regulators of the immune system. Nat Rev Immunol 2009; 9: 162-174.

25 Gregory SH, Sagnimeni AJ, Wing EJ. Bacteria in the bloodstream are trapped in the liver and killed by immigrating neutrophils. J Immunol 1996; 157: 2514-2520. 
26 Kenna T, Golden-Mason L, Norris S, Hegarty JE, O'Farrelly C, Doherty DG. Distinct subpopulations of gamma delta $T$ cells are present in normal and tumor-bearing human liver. Clin Immunol 2004; 113: 56-63.

27 Kenna T, Golden-Mason L, Porcelli SA, Koezuka Y, Hegarty JE, O'Farrelly $\mathrm{C}$ et al. NKT cells from normal and tumor-bearing human livers are phenotypically and functionally distinct from murine NKT cells. J Immunol 2003; 171: 1775-1779.

28 Dusseaux M, Martin E, Serriari N, Péguillet I, Premel V, Louis D et al. Human MAIT cells are xenobiotic-resistant, tissue-targeted, CD161 hi IL-17-secreting T cells. Blood 2011; 117: 1250-1259.

29 Gao B, Jeong W-I, Tian Z. Liver: an organ with predominant innate immunity. Hepatology 2008; 47: 729-736.

30 Hata K, Van Thiel DH, Herberman RB, Whiteside TL. Natural killer activity of human liver-derived lymphocytes in various liver diseases. Hepatology 1991; 14: 495-503.

31 Moroso V, Metselaar HJ, Mancham S, Tilanus HW, Eissens D, van der Meer $\mathrm{A}$ et al. Liver grafts contain a unique subset of natural killer cells that are transferred into the recipient after liver transplantation. Liver Transp/ 2010; 16: 895-908.

32 Lynch L, Michelet X, Zhang S, Brennan PJ, Moseman A, Lester C et al. Regulatory iNKT cells lack expression of the transcription factor PLZF and control the homeostasis of $T(\mathrm{reg})$ cells and macrophages in adipose tissue. Nat Immunol 2015; 16: 85-95.

33 Pruvot FR, Navarro F, Janin A, Labalette M, Masy E, Lecomte-Houcke M et al. Characterization, quantification, and localization of passenger $\mathrm{T}$ lymphocytes and NK cells in human liver before transplantation. Transp/ Int 1995; 8: 273-279.

34 Mehal WZ, Juedes AE, Crispe IN. Selective retention of activated CD8+ T cells by the normal liver. J Immunol 1999; 163: 3202-3210.

35 Huang L, Soldevila G, Leeker M, Flavell R, Crispe IN. The liver eliminates $\mathrm{T}$ cells undergoing antigen-triggered apoptosis in vivo. Immunity 1994; 1: 741-749.

36 Racanelli V, Sansonno D, Piccoli C, D'Amore FP, Tucci FA, Dammacco F. Molecular characterization of B cell clonal expansions in the liver of chronically hepatitis C virus-infected patients. J Immunol 2001; 167: 21-29.

37 Curry MP, Golden-Mason L, Doherty DG, Deignan T, Norris S, Duffy M et al. Expansion of innate CD5pos B cells expressing high levels of CD81 in hepatitis C virus infected liver. J Hepatol 2003; 38: 642-650.

38 Golden-Mason L, Curry MP, Nolan N, Traynor O, McEntee G, Kelly J et al. Differential expression of lymphoid and myeloid markers on differentiating hematopoietic stem cells in normal and tumor-bearing adult human liver. Hepatology 2000; 31: 1251-1256.

39 Crosbie OM, Reynolds M, McEntee G, Traynor O, Hegarty JE, O'Farrelly C. In vitro evidence for the presence of hematopoietic stem cells in the adult human liver. Hepatology 1999; 29: 1193-1198.

40 Taniguchi H, Toyoshima T, Fukao K, Nakauchi H. Presence of hematopoietic stem cells in the adult liver. Nat Med 1996; 2: 198-203.

41 Jiang $X$, Chen $Y$, Wei H, Sun R, Tian Z. Characterizing the lymphopoietic kinetics and features of hematopoietic progenitors contained in the adult murine liver in vivo. PLoS One 2013; 8: e76762.

42 Jenne CN, Kubes P. Immune surveillance by the liver. Nat Immunol 2013; 14: 996-1006.

43 Seki E, Brenner D. Toll-like receptors and adaptor molecules in liver disease: update. Hepatology 2008; 48: 322-335.

44 Böttcher JP, Schanz O, Wohlleber D, Abdullah Z, Debey-Pascher S, Staratschek-Jox A et al. Liver-primed memory $T$ cells generated under noninflammatory conditions provide anti-infectious immunity. Cell Rep 2013; 3: 779-795.

45 Yang L, Jhaveri R, Huang J, Qi Y, Diehl AM. Endoplasmic reticulum stress, hepatocyte CD1d and NKT cell abnormalities in murine fatty livers. Lab Invest 2007; 87: 927-937.

46 Yanagisawa K, Yue S, van der Vliet HJ, Wang R, Alatrakchi N, GoldenMason $L$ et al. Ex vivo analysis of resident hepatic pro-inflammatory CD1d-reactive $T$ cells and hepatocyte surface CD1d expression in hepatitis C. J Viral Hepat 2013; 20: 556-565.

47 Kelly AM, Golden-Mason L, Traynor O, Geoghegan J, McEntee G, Hegarty JE et al. Changes in hepatic immunoregulatory cytokines in patients with metastatic colorectal carcinoma: implications for hepatic anti-tumour immunity. Cytokine 2006; 35: 171-179.

48 Golden-Mason L, Kelly AM, Doherty DG, Traynor O, McEntee G, Kelly $\mathrm{J}$ et al. Hepatic interleuklin 15 (IL-15) expression: implications for local NK/NKT cell homeostasis and development. Clin Exp Immunol 2004; 138: 94-101.

49 Tu Z, Bozorgzadeh A, Crispe IN, Orloff MS. The activation state of human intrahepatic lymphocytes. Clin Exp Immunol 2007; 149: 186-193.

50 Tannahill GM, Curtis AM, Adamik J, Palsson-McDermott EM, McGettrick AF, Goel $G$ et al. Succinate is an inflammatory signal that induces IL-1 $\beta$ through HIF-1 $\alpha$. Nature 2013; 496: 238-242.

51 Tall AR, Yvan-Charvet L. Cholesterol, inflammation and innate immunity. Nat Rev Immunol 2015; 15: 104-116.

52 Tilg $\mathrm{H}$, Moschen AR. Evolution of inflammation in nonalcoholic fatty liver disease: the multiple parallel hits hypothesis. Hepatology 2010; 52: 1836-1846.

53 Csak T, Ganz M, Pespisa J, Kodys K, Dolganiuc A, Szabo G. Fatty acid and endotoxin activate inflammasomes in mouse hepatocytes that release danger signals to stimulate immune cells. Hepatology 2011; 54: 133-144.

54 Filipe A, McLauchlan J. Hepatitis C virus and lipid droplets: finding a niche. Trends Mol Med 2015; 21: 34-42.

55 Bar-Yishay I, Shaul Y, Shlomai A. Hepatocyte metabolic signalling pathways and regulation of hepatitis B virus expression. Liver Int 2011; 31: 282-290.

56 O'Neill LAJ, Pearce EJ. Immunometabolism governs dendritic cell and macrophage function. J Exp Med 2015; 213: 15-23.

57 Wilson GK, Tennant DA, McKeating JA. Hypoxia inducible factors in liver disease and hepatocellular carcinoma: current understanding and future directions. J Hepatol 2014; 61: 1397-1406.

58 Protzer U, Maini MK, Knolle PA. Living in the liver: hepatic infections. Nat Rev Immunol 2012; 12: 201-213.

59 Crispe IN. Immune tolerance in liver disease. Hepatology 2014; 60: 2109-2117.

60 Calne RY, Sells RA, Pena JR, Davis DR, Millard PR, Herbertson BM et al. Induction of immunological tolerance by porcine liver allografts. Nature 1969; 223: 472-476.

61 Lerut J, Sanchez-Fueyo A. An appraisal of tolerance in liver transplantation. Am J Transplant 2006; 6: 1774-1780.

62 Simpson N, Cho YW, Cicciarelli JC, Selby RR, Fong T-L. Comparison of renal allograft outcomes in combined liver-kidney transplantation versus subsequent kidney transplantation in liver transplant recipients: analysis of UNOS database. Transplantation 2006; 82 : 1298-1303.

63 Knolle $P$, Schlaak J, Uhrig A, Kempf $P$, Meyer zum Büschenfelde $K H$, Gerken G. Human Kupffer cells secrete IL-10 in response to lipopolysaccharide (LPS) challenge. J Hepatol 1995; 22: 226-229.

64 Callery MP, Mangino MJ, Flye MW. Kupffer cell prostaglandin-E2 production is amplified during hepatic regeneration. Hepatology 1991; 14: 368-372.

65 Groux H, Bigler M, de Vries JE, Roncarolo MG. Interleukin-10 induces a long-term antigen-specific anergic state in human CD4+ T cells. J Exp Med 1996; 184: 19-29.

66 Knolle PA, Uhrig A, Hegenbarth S, Löser E, Schmitt E, Gerken G et al. IL-10 down-regulates $T$ cell activation by antigen-presenting liver sinusoidal endothelial cells through decreased antigen uptake via the mannose receptor and lowered surface expression of accessory molecules. Clin Exp Immunol 1998; 114: 427-433.

67 Heymann F, Peusquens J, Ludwig-Portugall I, Kohlhepp M, Ergen C, Niemietz $\mathrm{P}$ et al. Liver inflammation abrogates immunological tolerance induced by Kupffer cells. Hepatology 2015; 62: 279-291.

68 De Creus A, Abe M, Lau AH, Hackstein H, Raimondi G, Thomson AW. Low TLR4 expression by liver dendritic cells correlates with reduced capacity to activate allogeneic $T$ cells in response to endotoxin. J Immunol 2005; 174: 2037-2045.

69 Bamboat ZM, Stableford JA, Plitas G, Burt BM, Nguyen HM, Welles AP et al. Human liver dendritic cells promote $T$ cell hyporesponsiveness. J Immunol 2009; 182: 1901-1911.

70 Goddard S, Youster J, Morgan E, Adams DH. Interleukin-10 secretion differentiates dendritic cells from human liver and skin. Am J Pathol 2004; 164: 511-519.

71 Kingham TP, Chaudhry UI, Plitas G, Katz SC, Raab J, DeMatteo RP. Murine liver plasmacytoid dendritic cells become potent immunostimulatory cells after Flt-3 ligand expansion. Hepatology 2007; 45: 445-454. 
72 Tokita D, Sumpter TL, Raimondi G, Zahorchak AF, Wang Z, Nakao A et al. Poor allostimulatory function of liver plasmacytoid DC is associated with pro-apoptotic activity, dependent on regulatory T cells. J Hepatol 2008; 49: 1008-1018.

73 Ichikawa S, Mucida D, Tyznik AJ, Kronenberg M, Cheroutre $\mathrm{H}$. Hepatic stellate cells function as regulatory bystanders. J Immunol 2011; 186: 5549-5555.

74 Wuensch SA, Spahn J, Crispe IN. Direct, help-independent priming of CD8+ T cells by adeno-associated virus-transduced hepatocytes. Hepatology 2010; 52: 1068-1077.

75 Bowen DG, Zen M, Holz L, Davis T, McCaughan GW, Bertolino P. The site of primary $T$ cell activation is a determinant of the balance between intrahepatic tolerance and immunity. J Clin Invest 2004; 114: 701-712.

76 Zimmermann HW, Bruns T, Weston CJ, Curbishley SM, Liaskou E, $\mathrm{Li} \mathrm{K}-\mathrm{K}$ et al. Bidirectional transendothelial migration of monocytes across hepatic sinusoidal endothelium shapes monocyte differentiation and regulates the balance between immunity and tolerance in liver. Hepatology 2015; 63: 233-246.

77 Sander LE, Sackett SD, Dierssen U, Beraza N, Linke RP, Müller M et al. Hepatic acute-phase proteins control innate immune responses during infection by promoting myeloid-derived suppressor cell function. J Exp Med 2010; 207: 1453-1464.

78 Moshage $\mathrm{H}$. Cytokines and the hepatic acute phase response. J Pathol 1997; 181: 257-266.

79 Gabay C, Kushner I. Acute-phase proteins and other systemic responses to inflammation. N Engl J Med 1999; 340: 448-454.

80 Zhou Z, Xu M-J, Gao B. Hepatocytes: a key cell type for innate immunity. Cell Mol Immunol 2015; e-pub ahead of print 21 December 2015; doi:10.1038/cmi.2015.97.

81 Inatsu A, Kinoshita M, Nakashima H, Shimizu J, Saitoh D, Tamai S et al. Novel mechanism of C-reactive protein for enhancing mouse liver innate immunity. Hepatology 2009; 49: 2044-2054.

82 Gregory SH, Wing EJ. Neutrophil-Kupffer cell interaction: a critical component of host defenses to systemic bacterial infections. J Leukoc Biol 2002; 72: 239-248.

83 Mosher B, Dean R, Harkema J, Remick D, Palma J, Crockett E. Inhibition of Kupffer Cells reduced CXC chemokine production and liver injury. J Surg Res 2001; 99: 201-210.

$84 \mathrm{Tu}$ Z, Bozorgzadeh A, Pierce RH, Kurtis J, Crispe IN, Orloff MS. TLR-dependent cross talk between human Kupffer cells and NK cells. J Exp Med 2008; 205: 233-244.

85 Pellicoro A, Ramachandran P, Iredale JP, Fallowfield JA. Liver fibrosis and repair: immune regulation of wound healing in a solid organ. Nat Rev Immunol 2014; 14: 181-194.

86 Bourbonnais E, Raymond V-A, Ethier C, Nguyen BN, El-Leil MS, Meloche $\mathrm{S}$ et al. Liver fibrosis protects mice from acute hepatocellular injury. Gastroenterology 2012; 142: 130-139.e4.

87 Hellerbrand C, Stefanovic B, Giordano F, Burchardt ER, Brenner DA. The role of TGFbeta1 in initiating hepatic stellate cell activation in vivo. J Hepatol 1999; 30: 77-87.

88 Ramachandran P, Pellicoro A, Vernon MA, Boulter L, Aucott RL, Ali $A$ et al. Differential Ly- $6 C$ expression identifies the recruited macrophage phenotype, which orchestrates the regression of murine liver fibrosis. Proc NatI Acad Sci USA 2012; 109: E3186-E3195.

89 Glässner A, Eisenhardt M, Krämer B, Körner C, Coenen M, Sauerbruch T et al. NK cells from HCV-infected patients effectively induce apoptosis of activated primary human hepatic stellate cells in a TRAIL-, FasL- and NKG2D-dependent manner. Lab Invest 2012; 92: 967-977.

90 Radaeva S, Sun R, Jaruga B, Nguyen VT, Tian Z, Gao B. Natural killer cells ameliorate liver fibrosis by killing activated stellate cells in NKG2D-dependent and tumor necrosis factor-related apoptosisinducing ligand-dependent manners. Gastroenterology 2006; 130 : 435-452.

91 Malato Y, Naqvi S, Schürmann N, Ng R, Wang B, Zape J et al. Fate tracing of mature hepatocytes in mouse liver homeostasis and regeneration. J Clin Invest 2011; 121: 4850-4860.

92 Michalopoulos GK. Liver regeneration. J Cell Physiol 2007; 213 : 286-300.

93 Cressman DE, Greenbaum LE, DeAngelis RA, Ciliberto G, Furth EE, Poli $V$ et al. Liver failure and defective hepatocyte regeneration in interleukin-6-deficient mice. Science 1996; 274: 1379-1383.
94 Akerman P, Cote P, Yang SQ, McClain C, Nelson S, Bagby GJ et al. Antibodies to tumor necrosis factor-alpha inhibit liver regeneration after partial hepatectomy. Am J Physiol 1992; 263: G579-G585.

95 Rai RM, Lee FY, Rosen A, Yang SQ, Lin HZ, Koteish A et al. Impaired liver regeneration in inducible nitric oxide synthasedeficient mice. Proc Natl Acad Sci USA 1998; 95: 13829-13834.

96 Selzner N, Selzner M, Odermatt B, Tian Y, Van Rooijen N, Clavien P-A. ICAM-1 triggers liver regeneration through leukocyte recruitment and Kupffer cell-dependent release of TNF-alpha/IL-6 in mice. Gastroenterology 2003; 124: 692-700.

97 Strey CW, Markiewski M, Mastellos D, Tudoran R, Spruce LA, Greenbaum LE et al. The proinflammatory mediators C3a and C5a are essential for liver regeneration. J Exp Med 2003; 198: 913-923.

98 Gao B, Radaeva S, Park O. Liver natural killer and natural killer T cells: immunobiology and emerging roles in liver diseases. J Leukoc Biol 2009; 86: 513-528.

99 Sun R, Gao B. Negative regulation of liver regeneration by innate immunity (natural killer cells/interferon-gamma). Gastroenterology 2004; 127: 1525-1539.

100 Shen K, Zheng S-S, Park O, Wang H, Sun Z, Gao B. Activation of innate immunity (NK/IFN-gamma) in rat allogeneic liver transplantation: contribution to liver injury and suppression of hepatocyte proliferation. Am J Physiol Gastrointest Liver Physiol 2008; 294: G1070-G1077.

101 Dong Z, Zhang J, Sun R, Wei H, Tian Z. Impairment of liver regeneration correlates with activated hepatic NKT cells in HBV transgenic mice. Hepatology 2007; 45: 1400-1412.

102 Seki E, Schwabe RF. Hepatic inflammation and fibrosis: functional links and key pathways. Hepatology 2015; 61: 1066-1079.

103 Karlmark KR, Weiskirchen R, Zimmermann HW, Gassler N, Ginhoux F, Weber $\mathrm{C}$ et al. Hepatic recruitment of the inflammatory Gr1+ monocyte subset upon liver injury promotes hepatic fibrosis. Hepatology 2009; 50: 261-274.

104 Bernardi M, Moreau R, Angeli P, Schnabl B, Arroyo V. Mechanisms of decompensation and organ failure in cirrhosis: from peripheral arterial vasodilation to systemic inflammation hypothesis. J Hepatol 2015; 63: 1272-1284.

105 Carbone M, Neuberger JM. Autoimmune liver disease, autoimmunity and liver transplantation. J Hepatol 2014; 60: 210-223.

106 Kedarisetty CK, Anand L, Bhardwaj A, Bhadoria AS, Kumar G, Vyas AK et al. Combination of granulocyte colony-stimulating factor and erythropoietin improves outcomes of patients with decompensated cirrhosis. Gastroenterology 2015; 148: 1362-70.e7.

107 Makarova-Rusher OV, Medina-Echeverz J, Duffy AG, Greten TF. The yin and yang of evasion and immune activation in HCC. J Hepatol 2015; 62: 1420-1429.

108 Kitamura T, Qian B-Z, Pollard JW. Immune cell promotion of metastasis. Nat Rev Immunol 2015; 15: 73-86.

109 Saeed S, Quintin J, Kerstens HHD, Rao NA, Aghajanirefah A, Matarese $\mathrm{F}$ et al. Epigenetic programming of monocyte-tomacrophage differentiation and trained innate immunity. Science 2014; 345: 1251086-1251086.

110 Ivashkiv LB, Donlin LT. Regulation of type I interferon responses. Nat Rev Immunol 2014; 14: 36-49.

111 Park S-H, Rehermann B. Immune responses to HCV and other hepatitis viruses. Immunity 2014; 40: 13-24.

112 Sangro B, Gomez-Martin C, de la Mata M, Iñarrairaegui $M$, Garraluda E, Barrera P et al. A clinical trial of CTLA-4 blockade with tremelimumab in patients with hepatocellular carcinoma and chronic hepatitis C. J Hepatol 2013; 59: 81-88.

(c) (1) $\Theta \odot$ This work is licensed under a Creative Commons Attribution-NonCommercial-NoDerivs 4.0 International License. The images or other third party material in this article are included in the article's Creative Commons license, unless indicated otherwise in the credit line; if the material is not included under the Creative Commons license, users will need to obtain permission from the license holder to reproduce the material. To view a copy of this license, visit http://creativecommons.org/licenses/by-nc-nd/4.0/ 